\title{
Questioning Inevitability: Investigating the Tragedy of the Commons
}

\author{
Stefan Suvajac ${ }^{1}$
}

\begin{abstract}
The Tragedy of the Commons is a common way to describe strategic interactions between gain-maximizing rational actors when faced with choices about consuming commonly held public goods. In the absence of a state authority or private property rights, the phrase and its accompanying theory posit that self-interested actors will invariably deplete commonly held resources when allowed to control access to them. This essay will formalize the tragedy of the commons as a prisoner's dilemma and show how the prisoners dilemma can be used to represent the over-use of commonly-held resources (while also modifying the prisoner's dilemma game to allow for incomplete information and state enforcement). By suggesting alternative analytical representations of the dilemma faced by actors in the commons, and exploring empirical cases of effective commons management systems enacted by the same communities that consume the common resource, this essay will show that that over-use (to the point of depletion) of a commons is not the inevitable outcome of individuals and communities governing the resources they use. Ultimately, the destiny of the commons is not unambiguously tragic.
\end{abstract}

Keywords: Environmental Policy, Resource Management, Tragedy of the Commons, Game Theory, Cooperation

\footnotetext{
${ }^{1}$ Department of Economics, McGill University. Address all correspondence to stefan.suvajac@mail.mcgill.ca.
} 


\section{Introduction}

Garett Hardin (1968) wrote (while also popularizing the phrase "tragedy of the commons"): “...when each man is locked into a system where it is rational to increase [production/consumption] without limit...ruin is the destination toward which all men rush, each perusing his own best interest in a society that believes in freedom of the commons. Freedom in a commons brings ruin to all." By "commons", Hardin means any nonexcludable, rivalrous, open-source public good and by "ruin" Hardin means total depletion of said resource beyond its carrying and regenerating capacity.[1] Finally, by "it is rational to increase without limit," Hardin means where the possibility of not benefiting from the consumption/use of a public (opensource, non-excludable) good, given others' ability to use it, makes it advantageous to consume/use under all circumstances.

To illustrate the inevitability of his conclusion, Hardin relies on a short (now archety pal) allegory. He asks the reader to imagine the interaction in a communal pasture, where any number of cattle (belonging to any gain-seeking herder) may freely graze. He suggests that each herder, as a rational and gain-maximizing agent, will conclude that it is free to perpetually add one additional unit to her herd. The herder will gain the entire benefit of adding an additional unit of cattle to the pasture, while only bearing a fraction of the cost (which is spread across all herders) of over-grazing or pollution. The same conclusion is reached by all rational and gain-seeking herders using this pasture. Ultimately, the logic mercilessly reproduces (accelerating in conditions where there are more actors) and the pasture is depleted, causing the collapse of the cattle population, while simultaneously erasing the gains and future productive capacity of the herders and field.

Whitehead (1948) writes: "The essence of tragedy... resides in the solemnity of the remorseless working of things...the inevitableness of destiny...the futility of escape." Hardin's logic is powerful, intuitive, deeply convincing and in the sense above, tragic. The structure of his argument is teleological. It points to a pre-ordained destiny and allows for only one logical outcome: total, 
inevitable and "tragic" depletion. The reader immediately recalls personal associations of communal sinks, dishes, a shared bag of chips, shared box of cookies, counter-tops, workspaces, bathrooms and classrooms being neglected or unfairly shared. Therein lies the power of Hardin's argument: accounts of situations where resources are open to all and controlled by users produce an inevitable and "remorseless" outcome. Hardin (1968) concludes that the only solutions to the tragedy of the commons are coercive and external state intervention or commons privatization. Thus, for a generation of economic and political theorists, a Leviathan or private property became the "only ways" to counter the inevitable catastrophic outcome implicit in a commonly shared resource.

Much of modern economic theory predicts Hardin's analysis is accurate. ${ }^{[1]}$ The existing and worsening state of anthropogenic climate change ${ }^{[2]}$ and the evident failure in this respect of the "invisible hand" [3] to fulfill its promise of the self-serving individual “...intend[ing] only his[her] own gain...[being led]...to promote the public interest..." also seems to support Hardin's claim. Surveys of grazing lands in Northern Scotland demonstrate that common grazing areas show more signs of environmental degradation then similar privately owned grazing areas.[1] Likewise, scepticism that individuals acting in their own selfinterest invariably leads to socially beneficial outcomes is ancient. To characterize depletion of the open-source commons, Aristotle wrote: “...what is common to the greatest number has the least care bestowed upon it. Everyone thinks chiefly of his[her] own, hardly at all of the common interest...".[4] Accounts of depletion, exploitation, destruction, and overuse of communal resources reflect distinctly and repeatedly off the mirrors of history[5] and again support Hardin's grim and challenging prediction about shared (non-excludable) and freely used (open-source) resources.

However, ultimately, Hardin's formidable account of freedom in the commons, and its inevitable, disastrous, trajectory is a metaphor. Like all metaphors, the tragedy of the commons is built on a narrative structure. Consequently, the generalizability and empirical validity of the tragedy of the commons is dependent on, "...the 
constraints that are assumed to be fixed for the purpose of analysis...[also]... being fixed in empirical settings unless authorities change them".[6] While the herders in Hardin's allegory cannot change the constraints of the situation in which they are imagined, real herders and fishers who use open-access and non-excludable common natural resources may be more capable of changing these constraints. As such, it is not obvious that empirical truth can be inferred from the metaphorical dilemma faced by the fictional herders of Hardin's allegory.

Throughout this paper, it will be shown that Hardin's "tragedy of the commons" is certainly a possible (perhaps even probable) outcome of strategic interactions between rational gainmaximizing agents in open-source, nonexcludable goods settings. Likewise, it challenges Hardin's assertion that the state and the market are the only solution to community control over resources nor “...uniformly successful in enabling individuals to sustain long term, productive use of natural resource systems". [6] Most importantly, this paper will demonstrate that the tragedy of the commons is not an inevitable and inescapable outcome of strategic interactions within open-source, nonexcludable goods settings.

\section{Formalizing Hardin's (1968)}

Tragedy of the Commons and

\section{Proposed Solutions}

The tragedy of the commons is often formalized by the prisoner's dilemma game. ${ }^{77 \mid 181}$ The prisoner's dilemma is a noncooperative game where players choose strategies in either dynamic or static settings. In non-cooperative games, cooperation, communication and alliances are impossible $[1]$ as dominant strategies. Furthermore, players are assumed to have perfect information. Here, perfect information implies players understand the full payoff matrix of the game.

In modelling Hardin's allegory, consider a field with a known carrying capacity ${ }^{[9]}$ of cattle. Let the $F$ represent this carrying capacity. In a game with two representative herders, there are two strategies: 1) defect, and; 2) cooperate. "Cooperate" is represented by allocating F/ 2 cattle to each herder. Defect involves the herder adding $>F / 2$ cattle to the field. 
Let the players' payoffs be: 20 units of profit each from cooperating, 0 units of profit for each where both defect, and should one player defect (while the other cooperates), 21 units of profit for the defecting player and -1 units of profit for the cooperating player. This game is visualized by the game matrix in Appendix A, Game 1.0. In this game, the dominant strategy for both players is to defect. In practical terms, this implies that each herders will (irrespective of the other herder's anticipated choice), as Hardin predicts, add beyond the carrying capacity of the field to the detriment of all (including the field). In this situation, the outcome chosen by the rational gainmaximizing herders is not pareto-optimal. Furthermore, the actions of individually acting rational individuals lead to a collectively irrational and pareto-inferior outcome, where both players would have preferred the cooperate, cooperate outcome. $[10]$

To remedy the situation, consider the models for Hardin's proposed solution: coercive external state intervention or private property.

In the first recommendation, Hardin (1978) suggests that "if ruin is to be avoided in a crowded world, people must be responsive to a "...'Leviathan'..." This policy advice is enacted as follows: 1) there is a state coercive power which defines the carrying capacity of the field; 2) the state authority decides who can use the field, and; 3) the state authority imposes fines in excess of the benefit from 'defecting' on those who choose it as their strategy. Following the parameters set out in Game 1.0, this means a penalty of at least 2 units of profit is imposed on players considered by the central authority to be playing a defect strategy. Assuming the same carrying capacity as Game 1.0, this updated game is visualized by the game matrix in Appendix A, Game 2.0. The game overseen by a Leviathan now yields the desirable and paretoefficient equilibrium cooperate, cooperate. The updated game assumes that the central authority has accurate information about carrying capacity, monitoring capability, sanctioning reliability and zero administrative cost.

Evidently, these are unrealistic assumptions. In keeping with Hardin's own commitment to realism, incomplete information will now be allowed. From Game 2.0, the central authority retains 
perfect information about carrying capacity and the administrative cost of zero continues. This game will be called Game 3.0 and its payoff matrix will appear in Appendix A. In Game 3.0, let y be the probability that the central authority punishes defectors correctly. Let $x$ be the probability that the central authority punishes cooperative action mistakenly. Notice that Game 2.0 is a special case of Game 3.0 where $x=0$ and $y=1$.6][11] In Game 3.0 with incomplete information, the central authority must punish defectors with a probability $>0.75$ and mistakenly punish cooperative behaviour with a probability $<0.25$ to avoid Game 1.0's traditional and undesirable defect, defect equilibrium. Game 4.0 shows that in a situation where the probabilities for accurate and consistent enframement are $y<0.75$ and $x>0.25$, the dilemma reverts to the undesirable and "catastrophic" defect, defect equilibrium. [12]

Finally, consider privatization. In Hardin's case, it is unclear what is meant by privatization. Presumably, in following the only pareto optimal "privatized" outcome, each herder would receive a large enough parcel of land to sustain $F / 2$ cattle. In this case, herders would need to incur costs to fence their portion off and incur costs to monitor the movements of the other Herder's crops. However, in non-idle situations (i.e. a flowing stream), it is not clear how private property would be used to ensure continued communal access.

\section{Alternative Representation of Public Goods Games}

Having formalized Hardin's account of the commons, the essay present three critiques of his presentation. From these critiques, alternatives to Hardin's presentation of strategic interactions in non-excludable, rivalrous, open-source public goods (commons) will be offered. In so doing, it will be shown that Hardin's insistence on tragic outcomes is the commons is incomplete and that show tragedy is not inevitable.

Firstly, at the formal level, the provision of goods in commons contexts can be represented through many different games.111] Even within the prisoner's dilemma game, there are multiple possible representations of the commons problem (ibid). For example, the chicken, assurance game and the 
hunter game can be construed as equally applicable to herders occupying the shared field. Consider the chicken game as an alternative (Appendix A, Game 5.0). The Chicken game would imply that one of the players has the capacity and incentive to deviate from the defect, defect equilibrium in order to avoid disastrous depletions. For the chicken game to represent the herder's predicament, the game's parameters would simply assume that the payoff for the worst off the herders in a potential cooperate, defect equilibrium is higher than the highest payoff yielded in a defect, defect equilibrium. Such a predicament is not unreasonable: it is entirely possible that the negative impacts of only one player defecting are lower than that of two.[13] Likewise, it is possible to produce some proportion of a public good (say, conserving the field), without providing the entirety of that public good. Another alternative it to model the field and the behaviour of herders using a NashCournot equilibrium where each herder anticipates the action of the other.

Secondly, consider the alternative, self-enforcing and self-funding contract game presented by Ostrom (1990) wherein herders produce a contract that binds them to a cooperate, cooperate equilibrium. In this self-financing game, herders hire an independent contract enforcer who, according to the estimates and agreements of the herders, enforces their cooperate, cooperate equilibrium. In Game 6.0, Appendix A, where this modified game appears, let $e$ be the cost of hiring an independent enforcer. All parameters and payoffs are the same as all previous herding prisoners dilemmas with a provision for agreeing or not agreeing to a binding contract. In this game, participants use the information they have, as users, without relying on a distant and coercive Leviathan (who, as shown, has a high probability of sanctioning error and possesses less information than resource users), to design their own contracts. Hardin ignores the potential for users to design their own contracts, and continue being users, without resort to private property or a coercive state.

Thirdly, in arguing for private property, Hardin ignores the discount rate of current consumption. In the case of a field being partitioned into private property, the herder may be equally well- 
incentivised to populate the field beyond its carrying capacity where market discount rates are relatively high. In the high discount rate scenario, the present value of future net benefits from conservation are extremely low. It would need to be the case that discount rates are relatively low for private property to incentivise sufficient and sustainable conservation of land and sustainable cattle populations.11][6] Consider an annuity which provides a payoff of 20 units/period for an infinite number of periods. This is the same payoff as from a cooperate, cooperate equilibrium (which is the result of using a field within its carrying capacity).With a discount rate of $10 \%$, the net present value of the future benefits from cooperate, cooperate equivalent annuity through private property is 200. Whereas at a discount rate of $1 \%$, the net present value is 2000 . The net present value represents the value of conservation from a cooperate, cooperate-like equilibrium: clearly, that value declines as discount rates increase. Thus, the future value of conservation declines as discount rates increase.

Finally, with respect to the Leviathan as a solution, it was clearly shown in the first section that public institutions must rely on extremely unrealistic assumptions in order to effectively enforce a paretoefficient equilibrium. No public enforcer exists without costs and no public institution possesses perfect information. ${ }^{[6]}$ Likewise, rates of accurate enforcement are regularly lower than $75 \%$. ${ }^{[6]}$ As such, in any situation where the consistent and accurate enforcement of punitive pareto-enforcing fines is in questions (say a corrupt and low expertise state apparatus), the efficacy of coercive power is brought deeply into question.

\section{Empirical Cases}

Communities in the Swiss Alps have managed systems for access to collective mountain pastures and forests managed and controlled by communities. Similarly, in Japan, comparable systems exist to control access to surrounding common forests and pastures. Finally, communities in Turkey and Greece have developed self-enforcing systems for portioning and allocating use of fisheries. In all listed cases, the users of the resource make all major decisions about how to manage the common resource. Though they develop institutions and contracts 
which bind actors, they do not resort to a distant and coercive Leviathan or privatization to produce optimal outcomes. In short, unlike Hardin's predictions, the communities do not relinquish control over their resources. As Picht (1987) writes: "The users are the main decision-making unit. They have to decide on all matters of importance and seem to have a considerable amount of autonomy in so doing." Likewise, in all cases presently discussed, the systems have existed for hundreds of years. In sum, the cases will show that even when presented with scenarios where over-use would be profitable and beneficial for community members, the resources have not been overused and communitycontrolled resource management systems (without state intervention or privatization) ensured sustainable resource over generations.

Some villages in the Swiss alps are characterized by a division of surrounding lands between private property and common use property. Private farming activities are carried-out on private land while communal summer grazing and lumber harvesting is carried out on communal land. The communities which use the common pastures and forests enact, enforce and amend rules which decide who from the community receives access to the common land. The mountain meadows and pastures are used for cattle grazing and the forest for providing valuable construction lumber. In many cases, up to $80 \%$ of the land considered part of these villages is controlled through some form of common holding. [13] i [15]

Similarly, in Japan, despite continued local community control and absence of privatization or state intervention, McKean (1982) has written that he has "not yet turned up an example that suffered ecological destruction while it was still a commons." Like Swiss alps villages, commons management systems in operation throughout Hirano, Nagaike, and Yamanoka, are confronted with a similar geographical environment: division between hillsides and forests. Households have private property for private farming while access to the communal forests provides a supply of lumber and herbs. As a unit, the household is the primary regulator of access to the forests. Additions to the household do not automatically imply 
more access to the common land, this additional access must be approved by a community council. The Japanese villages maintain (and have for hundreds of years) detailed statistical accounts of the number of households in their midst. Once harvesting opens, harvesting of both scarce and abundant plants could begin. For scarce plants, quotas are allocated to each family, and set based on the plants' fecundity, while abundant plants had no limits placed on their consumption. For timber, the whole community was mandated to contribute to harvesting and maintenance efforts of the forests to be entitled to a share. For enforcement, resource users hire detectives (who patrolled in pairs) to monitor access to the commons and penalize (while being entitled to a portion of the fine) those who are found in violation. The detective position is one of the most prestigious positions in the community, and the sanctions were graduated, moving from donations to community institutions to ejection from the community.[16] Like in the previous example, the community and direct resource users retained control of their resource and manage it efficiently without use of private property or centralized control from outside the community of users.

Finally, consider the famous common fishing areas in Alanya, Turkey. Throughout the 1970, the local fishing stocks had become seriously depressed due to over-fishing. The situation spurred conflict between fishers. The community enacted a cooperative which developed the following process: 1) define the eligible fishers (encompassing most of the community); 2) divide fishing locations; 3 ) assign initial fishing locations at random, and;4) all fishers rotate "on location" east daily so that all fishers have equal access to all locations (good and bad, while providing equal opportunity to catch from the migratory fish stock). The system is self-enforcing (it is obvious if a fisher is in the wrong location) and manages the fish stock efficiently ${ }^{[17]}$ without resorting to private property or coercive state intervention. Resource users developed systems for ensuring its efficient and sustainable use.

\section{Conclusion}

In conclusion, the theory built on Hardin's tragedy of the commons concludes strategic interactions within 
common resource settings are inevitably tragic. In these situations, the aggregated actions of rational and gain maximizing individual produces a collectively suboptimal outcome. In practical terms, the behavior of rational individual actors causes depletion at the expense of both the resource and the actors. As Ostrom (1990) writes, the tragedy of the commons and the analytical framework it provides have been used (and thus informed the worldview of decision-makers) to understand and characterize a wide-array of phenomena. These phenomena range from the problem of acid rain, to provisioning the developing-world with enough firewood, fishery policy, the inability of the US Government to limit its spending, urban crime, and collective bargaining. The tragedy of the commons and the notion of people being imprisoned in dilemmas of tragic depletion or over-exploitation when provisioning public goods has justified the expansion of centralized government control over community-controlled resources and mass-privatization of these same resources (particularly through the 1990s, and generally at the expense of local communities).
However, this essay presents an alternate view of interactions within common resource settings by the actors who use the resources. Firstly, it shows that through representing the commons dilemma as a chicken or self-enforcing commons game, it is possible to yield a pareto-optimal equilibrium. Likewise, it shows that the solutions proposed by Hardin are not certain to yield satisfactory pareto-optimal outcomes because: 1) partition into private property may not sufficiently incentivize conservation if the future net present value of those conservation efforts are low due to a relatively high discount rates, and; 2) demonstrating centralized coercive authorities' effectiveness in producing pareto-efficient outcome relies on excessively unrealistic assumptions (mainly, perfect information, accurate and consistent enforcement measures and no enforcement costs). Finally, three cases of effective commons management (sustainably over generations) by the same actors and communities who use them were provided and discussed. These communities escaped the prisoner's dilemma without using Hardin's solution. In these cases, communities and users 
retained control over their resource without privatization or reliance on external state control. The formal alternative representations, the critique of the Hardin's solutions, and historical examples showing outcomes different from those predicted by Hardin show that access to commons does not necessarily yield "tragedy". Most significantly, the essay shows that individuals are not mere prisoners of destiny in their efforts to provide public goods, retain control over community resource and regulate consumptions of commons. Likewise, they do not necessarily require guidance from centralized state power nor should their commonly held resources necessarily be subject to commodification and privatization.

Though this essay establishes that a tragic outcome is not inevitable in strategic interactions, it is not ignorant of where open-access to common resources produces tragedy. Climate change seems to be an area where action consistently demonstrates that the pareto-optimal outcome is not attained. Likewise, while history produces examples of effective commons management over many generations, it also produces the opposite[5]: Paleolithic (almost industrial) over-exploitation of mammal stocks, the destruction of Mesopotamian civilization because of soil erosion and the depopulation of Easter Island because of deforestation. Future research must be directed towards these areas where the prisoner's dilemma continues to bind the view of actors. The factors which differentiate effective and ineffective management of commons resources can be clearly elucidated in those cases. Furthermore, in studying these cases where there is persistent failure, more accurate games can be developed to help policy makers and communities understand how to generate paretooptimal and collectively rational outcomes. 


\section{Questioning Inevitability}

Appendix A:

Game 1.0

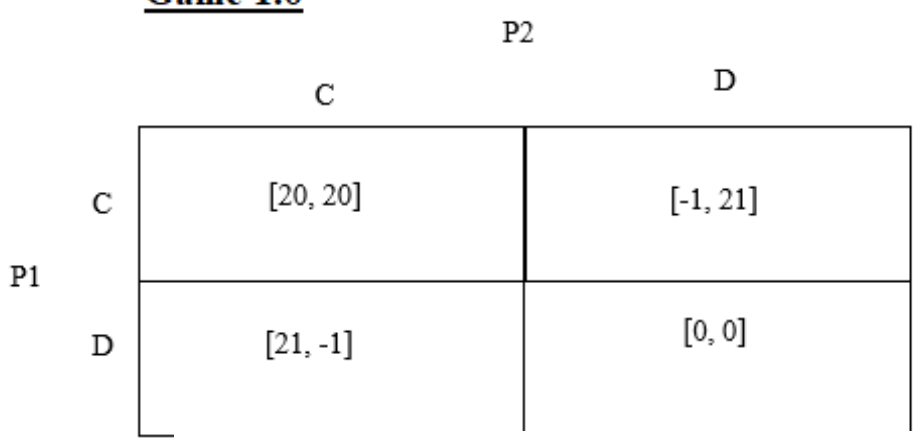

Game 3.0

\begin{tabular}{|c|c|c|}
\hline & \multicolumn{2}{|c|}{ P2 } \\
\hline & $\mathrm{C}$ & D \\
\hline $\mathrm{C}$ & {$[20-2 \mathrm{x}, 20-2 \mathrm{x}]$} & {$[-1-2 \mathrm{x}, 21-2 \mathrm{y}]$} \\
\hline $\mathrm{D}$ & {$[21-2 \mathrm{y},-1-2 \mathrm{x}]$} & {$[-2 y,-2 y]$} \\
\hline
\end{tabular}

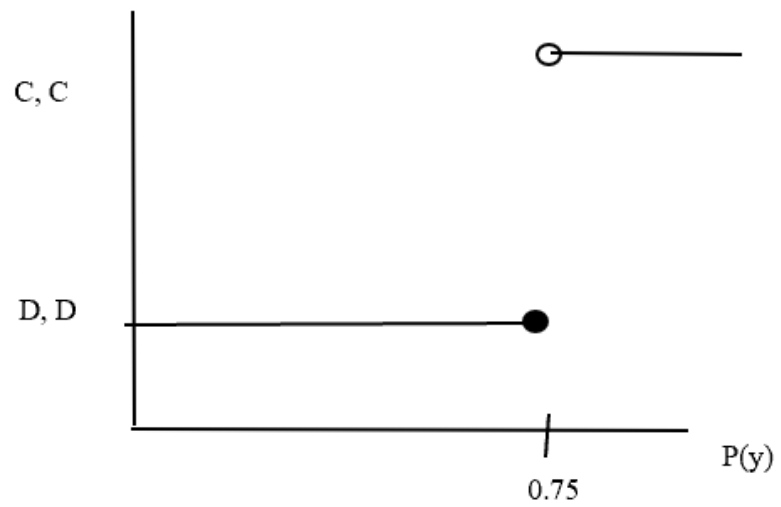

Game 2.0

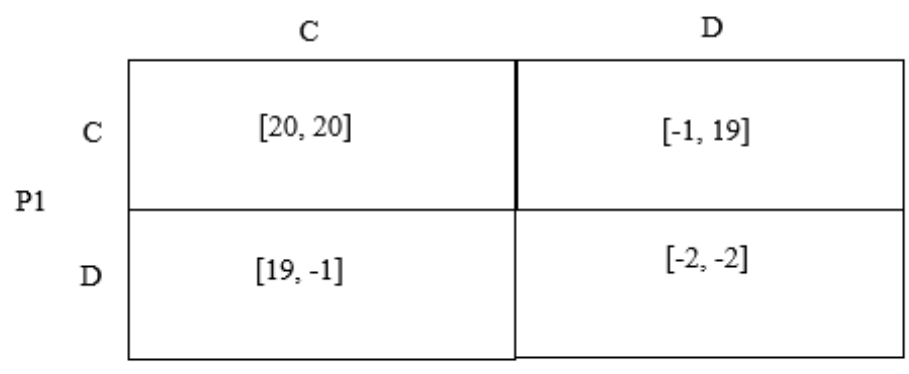

To have equilibrium at $[\mathrm{C}, \mathrm{C}], \mathrm{y}>0.75$. Otherwise, equilibrium will devolve to $\{D, D\}$.

Condition for equilibrium at $[\mathrm{C}, \mathrm{C}]$ is: $\mathrm{P} 2[\mathrm{C}, \mathrm{D}]<\mathrm{P} 2[\mathrm{D}, \mathrm{D}]-\mathrm{y}>0.75$ 


\section{McGill Journal of Human Behaviour}

Game 4.0

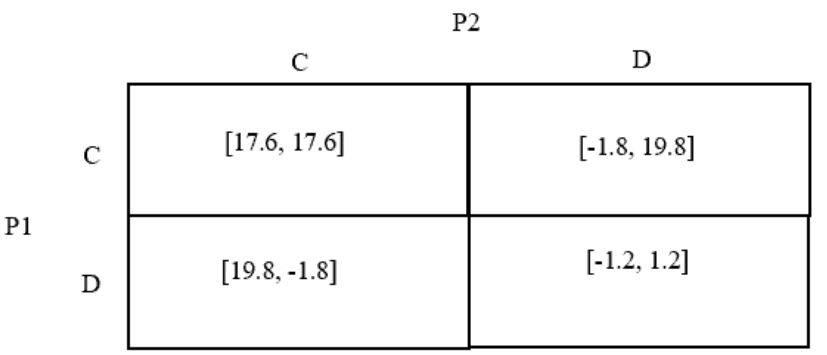

Game 5.0

Game 3.0 continued:

where $\mathrm{y}=0.6, \mathrm{x}=0.4$

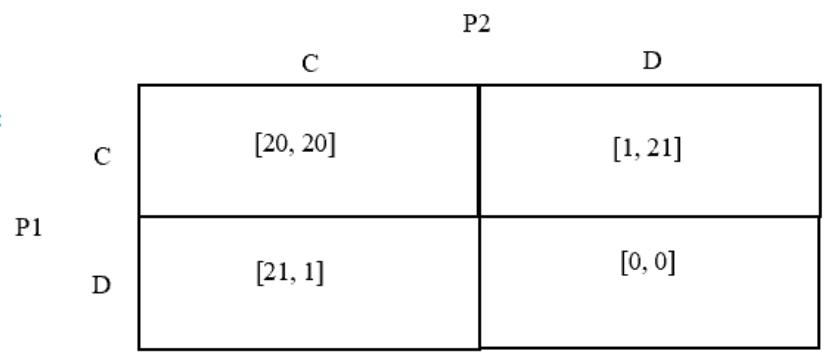

Game 6.0

$$
\begin{aligned}
& \text { C: Cooperate } \\
& \text { D: Defect } \\
& \text { A: Agree to binding contract } \\
& \text { A: Do not agree to binding contract } \\
& \text { e: Cost of enfrocement }
\end{aligned}
$$

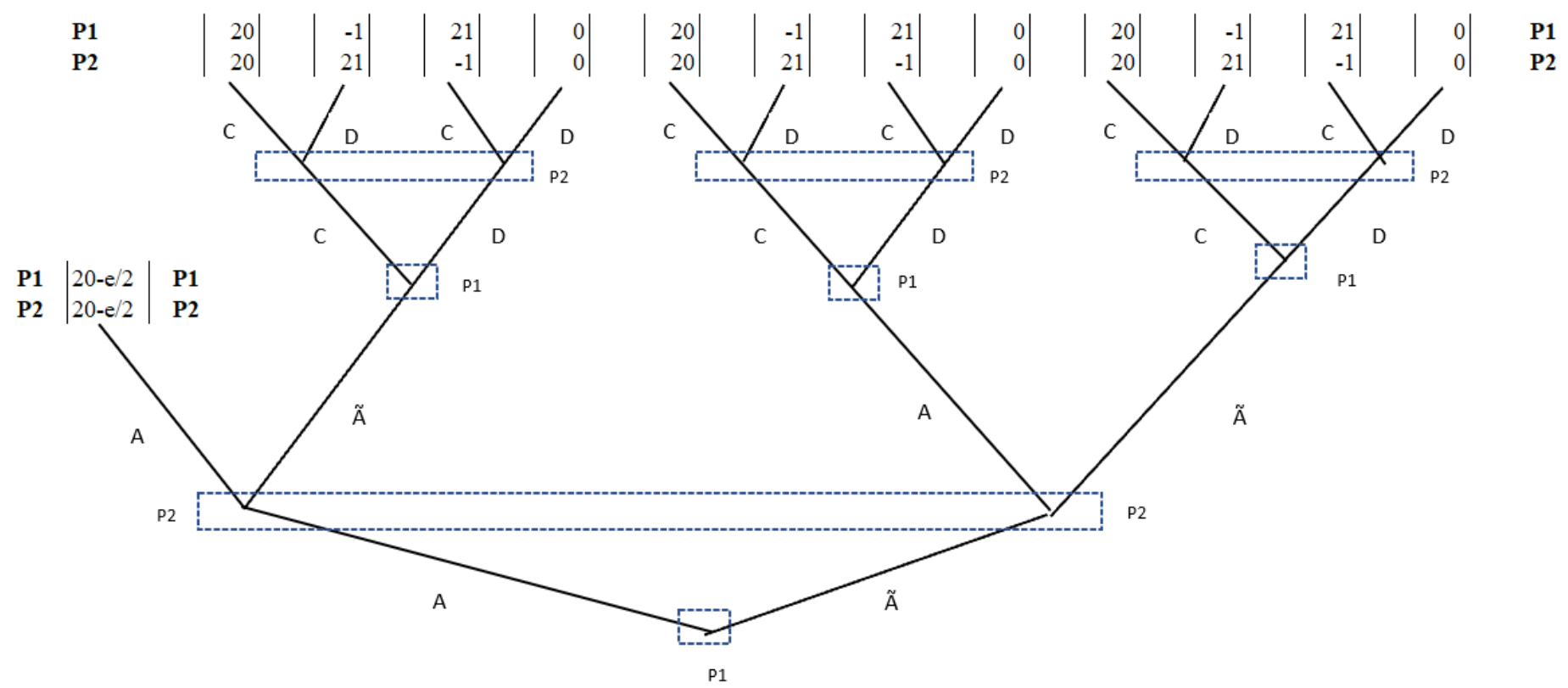




\section{References}

Aristotle, and Peter Simpson. 1997. The Politics of Aristotle. Chapel Hill: University of North Carolina Press.

Berkes, F. 1986. "Local-level management and the commons problem: a comparative study of Turkish coastal fisheries," Marine Policy 10: 215-29.

Dawes, R. M. 1973. The Commons Dilemma Game: An N-Person Mixed-Motive Game with a Dominating Strategy for Defection. ORI Research Bulletin 13:1-12.

Dawes, R. M. 1975. Formal Models of Dilemmas in Social Decision Making. In Human Judgment and Decision Processes: Formal and Mathematical Approaches, eds. M. F. Kaplan and S. Schwartz, pp. 87-108. New York: Academic Press.

Hanley, N., Shorgen, J. F. and White, B. 2013. Introduction to Environmental Economics: Second Edition, United Kingdom: Oxford University Press.

Hardin, G. 1978. Political Requirements for Preserving our Common Heritage. In Wildlife and America, ed. H. P. Bokaw, pp. 310-17. Washington, D.C.: Council on Environmental Quality.

Hardin, G. 1968. The Tragedy of the Commons. Science 162:1243-8.

IPCC (2018), Global Warming of 1.5 C: A Summary by Working Group I for Policy Makers, retrieved December 07/19, online: https:/ / www.ipcc.ch/2018/10/08/summaryfor-policymakers-of-ipcc-special-report-on-global-warming-of-1-5c-approved-bygovernments/

McKean, M. A. 1982. The Japanese Experience with Scarcity: Management of Traditional Common Lands. Environmental Review 6:63-88.

Netting, R. McC. 1976. What Alpine Peasants Have in Common: Observations on Communal Tenure in a Swiss Village. Human Ecology 4:135-46.

Ostrom, E. 1990. Governing the Commons. Cambridge: Cambridge University Press.

Picht, C. 1987. Common Property Regimes in Swiss Alpine Meadows. Paper presented at a conference on advances in comparative institutional analysis at the InterUniversity Center of Postgraduate Studies, October 19-23, Dubrovnik,Yugoslavia.

Rosen, Harvey S, Wen Jean-François, and Tracy Snoddon. 2012. Public Finance in Canada Fifth Canadian ed. Whitby, Ont.: McGraw-Hill Ryerson.

Smith, A. 1776. The Wealth of Nations, Modern Library: New York.

Taylor, M. 1987. The Possibility of Cooperation. Cambridge University Press.

Whitehead, Q. N. 1948. Science and the Modern World. Mentor, New York.

Wright, Ronald. 2011. A Short History of Progress. CBC Massey Lecture. New York: House of Anansi Press.

[1] Hanley, N., Shorgen, J. F. and White, B. 2013. Introduction to Environmental Economics: Second Edition, United Kingdom: Oxford University Press. 


\section{McGill Journal of Human Behaviour}

[2] IPCC (2018), Global Warming of 1.5ㄷ: A Summary by Working Group I for Policy Makers.

[3] Smith, A. 1776. The Wealth of Nations, Modern Library: New York.

[4] Aristotle, and Peter Simpson. 1997. The Politics of Aristotle. Chapel Hill: University of North Carolina Press. Book II, ch.3.

[5] Wright, Ronald. 2011. A Short History of Progress. CBC Massey Lecture. New York: House of Anansi Press.

[6] Ostrom, E. 1990. Governing the Commons. Cambridge: Cambridge University Press.

[7] Dawes, R. M. 1973. The Commons Dilemma Game: An N-Person Mixed-Motive Game with a Dominating Strategy for Defection. ORI Research Bulletin 13:1-12.

[8] Dawes, R. M. 1975. Formal Models of Dilemmas in Social Decision Making. In Human Judgment and Decision Processes: Formal and Mathematical Approaches, eds. M. F. Kaplan and S. Schwartz, pp. 87108. New York: Academic Press.

[9] The upper bound number of cattle which can graze and be well fed without negatively affecting the consumption of the other herder's (Ostrom 1990). This game assumes cattle consumption is symmetric.

[10] Hardin's game is best represented by a prisoner's dilemma. As noted by Ostrom (1990) and others (Taylor 1987), there are other options for representing common pool resources which are less static, involve several moves or are event simple configurations of the tragedy of the commons into simple chicken games. More on this in the following section.

111 Taylor, M. 1987. The Possibility of Cooperation. Cambridge University Press.

[12] Ostrom (1990) and Taylor (1987) show the sum of probabilities for correct enforcement and incorrect punishment of punitive behaviour must be one.

[13] Rosen, Harvey S, Wen Jean-François, and Tracy Snoddon. 2012. Public Finance in Canada Fifth Canadian ed. Whitby, Ont.: McGraw-Hill Ryerson.

[14] Picht, C. 1987. Common Property Regimes in Swiss Alpine Meadows. Paper presented at a conference on advances in comparative institutional analysis at the Inter-University Center of Postgraduate Studies, October 19-23, Dubrovnik, Yugoslavia.

[15] Netting, R. McC. 1976. What Alpine Peasants Have in Common: Observations on Communal Tenure in a Swiss Village. Human Ecology 4:135-46.

[16] McKean, M. A. 1982. The Japanese Experience with Scarcity: Management of Traditional Common Lands. Environmental Review 6:63-88.

[17] Berkes, F. 1986. "Local-level management and the commons problem: a comparative study of Turkish coastal fisheries," Marine Policy 10: 215-29. 